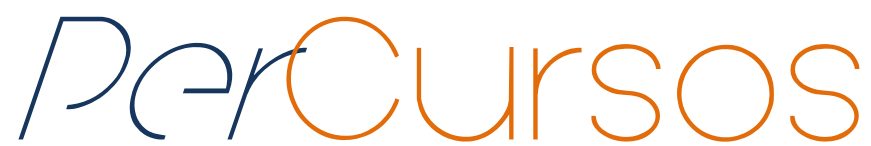

\title{
Migraciones y cambios: trayectorias, identidades y transformaciones de inmigrantes brasileños en Portugal
}

\section{Resumen}

Este trabajo aborda la temática de la migración y sus efectos transformadores en las esferas individual, social e identitaria, según es sufrida por los/las inmigrantes, mostrando como modelan los procesos de adaptación e integración en el país de destino. Estos cambios y transformaciones son ejemplificados recurriendo a narrativas de inmigrantes brasileños residentes en Portugal. Diferenciamos los cambios que experimentan en tres grandes categorías: a) los que ocurren a nivel personal, en las formas de socializar y de sentir, b) los que se relacionan con el tipo de empleo y experiencia laboral, y c) los que suceden en las identidades. Dentro de los cambios identitarios se destacan la identidad nacional, que adquiere gran relevancia, así como la identidad de género que en Portugal deriva en estigmatización.

Palabras clave: Brasileños; Brasileñas; Cambios; Percepción del inmigrante; Identidades; Portugal.

\section{Beatriz Padilla}

Doutora em Sociologia pela Universidade de Illinois em Urbana-Champaign - Estados

Unidos. Professora e pesquisadora na Universidade do Minho - Portugal. padilla.beatriz@gmail.com

\section{Para citar este artigo:}

PADILLA, Beatriz. Migraciones y cambios: trayectorias, identidades y transformaciones de inmigrantes brasileños en Portugal. Revista PerCursos. Florianópolis, v. 15, n. 28, p. 06 - 41, jan./jun. 2014.

DOI: $10.5965 / 1984724215282014006$

http://dx.doi.org/10.5965/1984724215282014006 
Migrações e mudanças: trajetórias, identidades e transformações de imigrantes brasileiros em Portugal

\begin{abstract}
Resumo
O presente trabalho aborda a temática da migração e seus efeitos transformadores nas esferas individual, social e identitária, como é sofrida pelos/as imigrantes, mostrando como modelam os processos de adaptação e integração no país de destino. Estas mudanças e transformações são ilustrados utilizando as narrativas de imigrantes brasileiros residentes em Portugal. Diferenciamos as mudanças experimentadas em três grandes categorias: a) as que acontecem a nível pessoal, nas formas de socializar e de sentir, b) as que se relacionam com o tipo de emprego e experiência laboral, e c) as que modelam as identidades. Entre as mudanças identitárias destacam-se a identidade nacional, que ganha relevância, e a de gênero que em Portugal deriva em estigmatização.
\end{abstract}

Palavras-chave: brasileiros; mudanças; percepção do imigrante; identidades; Portugal.
Migration and change: trajectories, identities and transformations experienced by Brazilians in Portugal

\begin{abstract}
This article is about migration and its transformative effects at the individual, social and identity levels, as experienced by immigrants, showing how they shape the processes of adaptation and integration in the destination country. These changes and transformations are illustrated using the narratives of Brazilians immigrants living in Portugal. We contrasts the transformations experienced in three categories: a) those that take place at the personal level, on the ways of socialization and feelings, b) those related with the type of jobs and the labor market experience, and c) those that shape their identities. Within identity changes, national identity becomes relevant, as well as gender identity, which in Portugal turns into stigmatization.
\end{abstract}

Keywords: Brazilians, changes, immigrants' perception, identities, Portugal 
Si bien la globalización impulsa la libre movilidad de los factores de producción, las barreras a la circulación de las personas, en lugar de disminuir, han aumentado. Los estados restringen cada vez más la inmigración. En este sentido Lelio Mármora (2002) afirma que "antes que una paradoja, los obstáculos a la movilidad de las personas responden a la lógica de una globalización unilateral, monopólica y excluyente". Esta visión restringida deshumaniza a las personas que migran, negándoles, generalmente, un estatuto legal y fragilizando su situación en el país de destino.

Este trabajo no visualiza al inmigrante en una situación de desempowerment ni lo considera un "desgraciado", sino que lo reconoce como un sujeto con agencia y con capacidad de decidir sobre su destino, aunque sea limitada. Sin embargo, no podemos dejar de considerar las dificultades y peripecias que significa migrar, ya que este proceso genera en los inmigrantes un conjunto de incertidumbres y cambios que lo afectan profundamente en diferentes esferas (LACOMBA 2001). Pretendemos describir los diferentes tipos de cambios y transformaciones que los inmigrantes experimentan en las esferas llamadas psicosocial, laboral-profesional, e identitaria, en las cuales se incluyen tanto la identidad de clase, la nacional, la étnico-racial, y la de género.

Si bien la literatura sobre inmigración tanto desde la sociología como desde la antropología, ha dedicado esfuerzos a estudiar la adaptación e integración de los inmigrantes, se sabe mucho menos sobre los cambios y alteraciones que los inmigrantes realizan y sufren a nivel de la personalidad y de los comportamientos desde una perspectiva antroposociológica, permitiéndonos conocer lo que hacen para sentirse adaptados, integrados y muchas veces, solo acostumbrados. Por ello se hace necesario profundizar e reflexionar sobre la forma de abordar sociológica y antropológicamente “aspectos como el cambio, la pérdida, la discontinuidad y la añoranza de continuidad y generacional, así como las diferencias de poder" (GAILLY, 2010, p.51).

Aunque los procesos migratorios son antiguos, sólo recientemente algunas investigaciones, sobre todo en el área de la salud, han señalado y documentado algunos problemas que los inmigrantes suelen experimentar como depresiones, un alto grado de estrés, entre otras situaciones. Algunos investigadores lo han denominado "síndrome de Ulises" (ESCUDERO 2004), aunque también existe una gran controversia sobre si esta 
situación puede ser considerada una enfermedad clínicamente detectable, ya que la migración en realidad actúa como un factor catalizador de ciertas situaciones comunes en procesos y contextos migratorios marcados por el estrés. Esto es así especialmente si consideramos que la inmigración conlleva a la pérdida de una serie de objetos significativos, causadas por el distanciamiento de las redes sociales y familiares conocidas, de la lengua y códigos culturales, y por el cambio de estatus social que implican cambios en sus constelaciones identitarias, que le es recordado de manera constante por su condición de extranjero (Lurbe i Puerto 2007, p. 60). En este artículo, profundizamos este análisis aplicándolo a la experiencia de los inmigrantes brasileños residentes Portugal.

\section{Metodología}

La metodología adoptada es esencialmente cualitativa, combinando entrevistas y trabajo de carácter etnográfico de observación participante. Los datos empíricos provienen de40 entrevistas en profundidad realizadas con brasileñas y brasileños, autoidentificados como pertenecientes a clase media y media baja (trabajadora), en la primera década del Siglo XXI, originarios de diferentes regiones de Brasil, residentes mayoritariamente el Área Metropolitana de Lisboa. Asimismo, se incorporan consideraciones obtenidas en entrevistas con líderes de asociaciones civiles y de inmigrantes brasileños.

Además, se realizó un estudio de caso a través de una etnografía multisituada (MARCUS, 1995) que envolvió la realización de trabajo de campo cualitativo (observación participante, entrevistas y socialización) con inmigrantes provenientes del Estado de Mato Grosso do Sul y sus familias. Este trabajo etnográfico incluyó a familias inmigrantes brasileñas radicadas en un barrio popular de Lisboa, y a sus familiares y amigos residentes en Brasil, principalmente en la ciudades de Dourados e Itaporã y en menor medida en Campo Grande. Para esta fase específica, se abordó a las familias brasileñas residentes en el mencionado barrio, conviviendo con ellas, compartiendo momentos de socialización, aunque también realizando entrevistas y visitas a sus hogares. Esta convivencia permitió y 
facilitó el contacto con las familias en la región de origen, las que abrieron sus casas y corazones, para contar cómo vivían la migración de sus familiares y amigos, desde la región de origen, ya sea sintiendo la falta de los seres queridos o esperando por el retorno.

Debido a que los datos empíricos confluyen de dos abordajes diferentes, el análisis de los mismos es variado. Cuando apropiado, se cuantifican algunas generalizaciones en porcentajes, con el objetivo de identificar las principales tendencias, aunque se reconoce esta limitación. Conviene aclarar que los testimonios y generalizaciones se incorporan son las opiniones y sentimientos expresados por los protagonistas y no los de la autora.

\section{Brasileños en Portugal: perfiles y trayectorias}

Los/as brasileños/as representan desde 2007 la mayor comunidad inmigrante en Portugal, y a partir de 2003 los flujos comienzan una nueva tendencia: la feminización, que se va consolidando hasta el presente, llegando al 58\%. La llegada de los brasileños a Portugal implicó un cambio substancial en la composición de los flujos migratorios que se caracterizaban por el predominio de los inmigrantes provenientes de los países africanos de lengua oficial portuguesa, conocidos como PALOPs (BAGANHA y GÓIS 1999; GÓIS et al 2009). Hasta 2006 los inmigrantes de Cabo Verde habían tenido preponderancia, sin embargo con el aumento significativo de los flujos provenientes de Brasil, a partir de mediados de los años 90, la comunidad brasileña creció de modo sostenido, evolucionando también el perfil típico de los inmigrantes. En 2012 representaban la nacionalidad extranjera más numerosa, alcanzando el $25 \%$.

Las olas migratorias brasileñas en Portugal se caracterizaron inicialmente por estar compuestas por los exiliados, los descendientes de portugueses y los altamente calificados, especialmente entre la década de 1970 y 1990. La ola siguiente, a partir de fines de los años 1990s, se caracterizó por un perfil diversificado, menos calificado que respondía a la necesidad de mano de obra en la construcción y en los servicios (PADILLA 2004b, 2006a, PEIXOTO y FIGUEREDO 2007), sin embargo desde fines de la primera década de 2000, los flujos han mostrados nuevas variantes, por un lado el incremento de 
estudiantes internacionales y por el otro en contraflujo, o sea el retorno de los ciudadanos brasileños como causa de la crisis en Europa y del crecimiento económico en Brasil (PADILLA, 2012; PADILLA y ORTIZ, 2012) que ha significado una reducción en el número de brasileños residentes. Actualmente, la diversidad dentro de la comunidad brasileña abarca varios aspectos, desde los diversos estatutos legales, estratos socioeconómicos y perfiles profesionales, mientras que el común denominador es la edad económicamente activa.

¿Cómo caracterizar a la inmigración brasileña en Portugal? Si bien concordamos Con LESSINGER (1995, p.71-72) en que "la investigación actual ve el ímpetu de la migración como una situación muy compleja tanto para el individuo como para grupos enteros de individuos" y que "los factores de atracción y de expulsión operan simultáneamente", por lo que "no existe un único perfil del migrante típico", es posible realizar una generalización identificando algunos casos típicos desde perspectivas macro y micro. En lo macro, puede afirmarse que es una inmigración laboral de calificación intermedia, aunque en muchas ocasiones se desempeñen en trabajos de poca calificación. Inicialmente, desde fines de 1990 hasta mediados de 2000, respondieron a la necesidad de mano en Portugal, buscando alternativas que no encontraron en el país de origen, debido a la falta de oportunidades. En una perspectiva micro, la inmigración brasileña fue alimentada y reforzada por la existencia de redes sociales y familiares que ejercieron gran atracción, reclutando más miembros. Así las historias de inmigración articulan lo macro con lo micro, pero a la vez se diferencian por alguna situación específica y particular que define dicha migración. La Figura 1 resume lo expuesto, listando algunas de las características macro y micro relacionadas con los perfiles de los inmigrantes brasileños. 
Figura 1- Características Macro y Micro que definen los perfiles de los inmigrantes

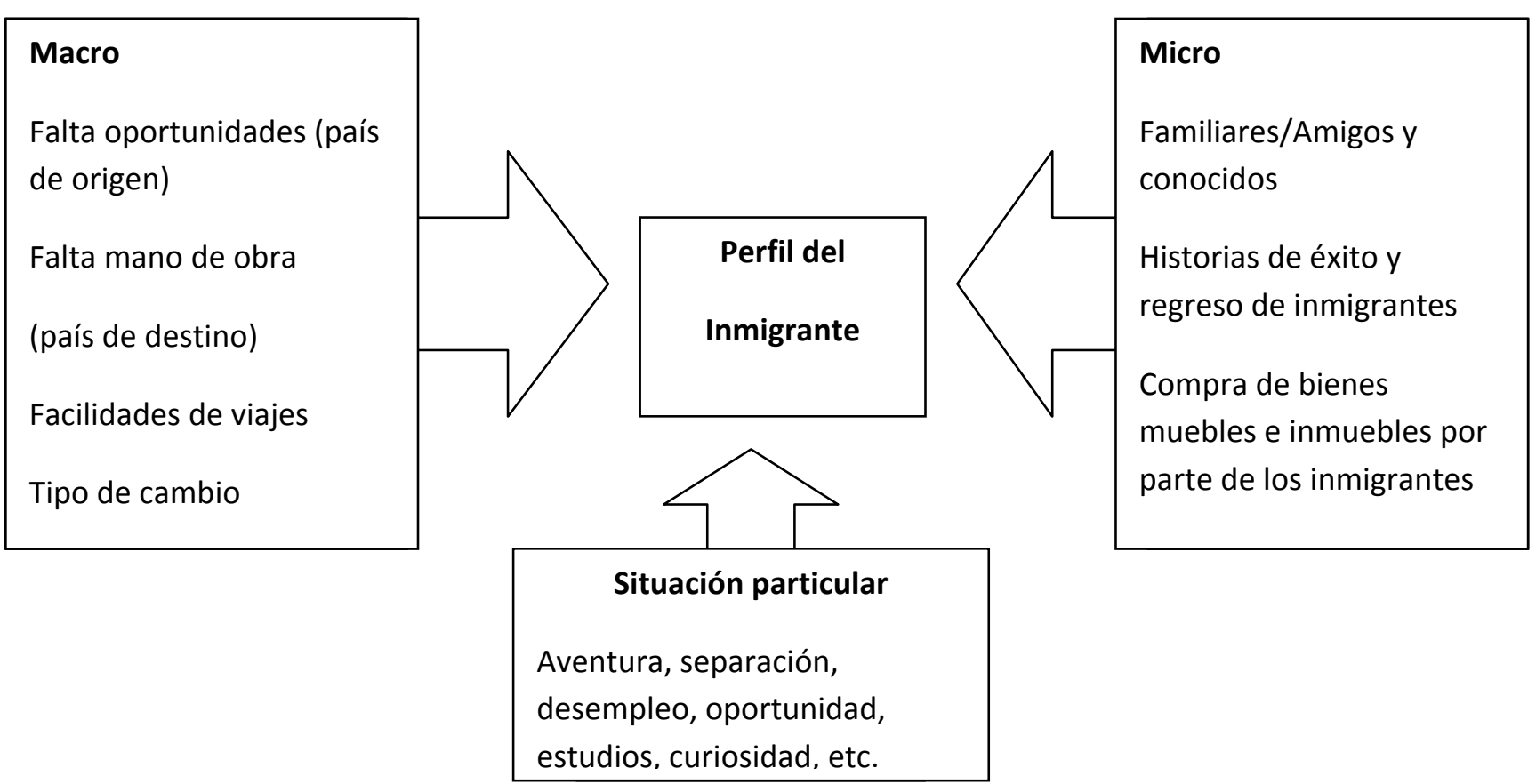

Por ejemplo Copelito emigró a Portugal porque hizo una apuesta después de haber tomado varias cervezas, y medio borracho desafió a otro colega a emigrar. Si bien su historia parece fuera de contexto, la verdad es que se inserta en las necesidades del mercado internacional (macro), ya que cuando emigró, hacen más de 15 años, existía en Portugal una necesidad de mano de obra, sobre todo en la construcción, donde consiguió trabajo casi inmediatamente. Por otro lado, no emigró solo, sino que arrastró a su cuñado y a un amigo en su aventura. Este grupo de tres amigos constituyen la semilla inicial de una red social con origen en las ciudades de Dourados-Itaporã, de Mato Grosso do Sul (micro). Como parte de esta misma red, aunque con ramificaciones posteriores, llegaron muchos otros inmigrantes de esa región, que trasplantarían sus conexiones en Lisboa. Entre ellos, llegó Juliana, con la ilusión de ganar dinero rápidamente, para replicar ella misma una de las muchas historias de éxito de las cuales tomó conocimiento entre sus redes sociales, cuando regresaban a Brasil, de forma definitiva o de visita. Estas historias relataban el auge de la economía portuguesa y la posibilidad de ganar y ahorrar dinero rápidamente. Sin embargo, a la llegada encontró un panorama diferente, la economía se 
había desacelerado y se dio cuenta que tal vez nunca había sido tan dinámica como las historias contaban. De cualquier manera, optó por quedarse en Lisboa, y al momento de la entrevista llevaba dos años en Portugal. Juliana se había separado del marido antes de venir, y dejó dos hijos adolescentes con sus padres, y su proyecto migratorio estaba relacionado con un intento por rehacer su vida, buscando también una cierta liberación de los compromisos familiares que dejó atrás, y de vivir la vida, porque se había casado muy joven.

\section{Migración como escenario transnacional}

El enfoque de este trabajo es transnacional. Articula conjuntamente la sociedad de origen y la de destino. El transnacionalismo es "un proceso social donde los inmigrantes operan en campos sociales que transgreden las fronteras geográficas, políticas y culturales" (BRETTELL, 2000, p.104). Por ello, los inmigrantes mantienen en su mayoría lazos con su país de origen, conservan y recrean también, ya en la sociedad de recepción, lazos originados en el país de origen, y además desarrollan nuevos lazos, fuertes y débiles, en la sociedad de destino (PADILLA, 2006b). Como dice Margolis (1995, p.29), hacen "del país de origen y de destino una única arena de acción social”. Esta arena de acción social común existe entre los brasileños inmigrantes que viven en gran número en el barrio popular de Lisboa y en las localidades de Mato Grosso do Sul, según pude observar en el trabajo de campo. Si bien la distancia geográfica separa a las familias, en muchos aspectos consiguen vivir como si estuviesen próximos, compartiendo los principales sucesos y noticias, cada vez más facilitadas por la televisión, la Internet y las comunicaciones telefónicas. Las familias y amigos residentes en Brasil saben casi al instante lo que sucede en los hogares de sus familiares y amigos en Lisboa y viceversa, si tienen trabajo, si alguien está enfermo o si algo bueno o malo les sucedió. Incluso el hecho que algunas vivencias y experiencias se acallen o se destaquen, tanto en un lado como en el otro, refuerza la idea que las familias viven vidas transnacionales, ancladas en ambos contextos, si bien más orientadas en origen o destino, según la localización. Citando a Glick-Schiller, Basch y Blanc-Szanton (1992), Parella (2007, p.153) sostiene que: 


\begin{abstract}
"Existe cada vez más consenso entre los investigadores a la hora de reconocer que algunos migrantes y sus descendientes están fuertemente influenciados por sus continuos vínculos con su país de origen o por redes sociales que sobrepasan las fronteras nacionales."
\end{abstract}

En el caso del trabajo de campo desarrollado en Dourados-Itaporã, la visita fue vivida por mí, por la mayoría de los inmigrantes en Lisboa y por sus familiares y amigos que me recibieron en Brasil, en un escenario transnacional, con un seguimiento telefónico y de otras tecnologías de la información y la comunicación por parte todos, especialmente de los inmigrantes residentes en Lisboa, que con mucha ansiedad querían que les trasmitiese lo que pasaba/veía/vivía/intuía en sus casas y barrios, con sus familias, haciendo con que ellos de cierta manera estuvieran cerca, conmigo, viviendo parte de mi experiencia. La etnografía multisituada me convirtió en una especie de intermediaria de y entre las emociones en ambos lados del Atlántico, además de las propias, que muchas veces eran muy fuertes y tenían un impacto psicológico fuerte en el estado de ánimo, en la forma de recibir y procesar noticias sobre los miembros de la familia incluyendo su bienestar, sentimientos positivos y negativos hacia sus familiares, las condiciones socioeconómicas en las que vivían y la circunstancias específicas que atravesaban.

A mi regreso, una situación semejante de ansiedad a la sentida durante la estadía en Dourados, se repitió. Todos, brasileñas y brasileños residentes en Lisboa que eran parte de la etnografía multisituada, mostraron gran curiosidad por saber de sus familias, de sus pertenencias, de su ciudad, de su barrio, se su tierra. Además querían ver las fotografías recientes que traía conmigo, sobre toda aquella realidad que hacía tiempo que no veían ni sentían.

Como intermediaria, transporté entre mis pertenencias y en ambas direcciones, elementos que ponían en contacto las familia en ambos lados de Atlántico. Llevé conmigo varias encomiendas: una infaltable virgen de Fátima (que ocupaba la mitad de la pequeña valija con la que viajé), varios productos de "tocador" como jabones, cremas y perfumes, y fotografías de los/las inmigrantes para mostrar a sus familiares y amigos. Las fotografías fueron un elemento clave en las relaciones establecidas, ayudaron a abrir las puertas y los brazos de las personas con quien interactué en ambos extremos del Atlántico. 
Traje conmigo más productos de "tocador" jabones, cremas, perfumes con olores de Brasil, dulces y otros alimentos brasileños con sabores de Brasil, y muchas fotografías de las familias junto a mí. El elemento común en los productos que traje, era la nostalgia, "saudade" de la familia y seres queridos, tanto de Brasil en general como y de la región visitada.

Este escenario transnacional entre vínculos, emociones y afectos, nos permite explorar de forma más cercana las continuidades, rupturas y cambios que son consecuencia de las "fracturas espaciales" (PARELLA, 2007) entre familiares, cónyuges, padres/madres e hijos/as. De las fracturas espaciales del escenario transnacional algunos sobresalieron como más relevantes y permanentes en los vínculos y relaciones migratorios entre las sociedades de origen y de destino. Uno de los ejes lo constituyó la temática relacionada con la salud (buena/mala; enfermedades; envejecimiento; muertes; nacimientos) y el otro, los asuntos familiares (cómo la familia "lleva" la ausencia de quien emigró, la compensación económica por dicha ausencia, el "abandono" de los hijos u otros miembros de la familia como los padres ancianos, etc.). Estos asuntos fueron sentidos como los más transnacionales y vividos "en carne propia” aunque la distancia los separe.

Por ello, la "perspectiva transnacional proporciona un nuevo marco analítico que visibiliza la creciente intensidad de los flujos poliédricos de personas, objetos, información y símbolos y permite analizar cómo los migrantes construyen y reconstruyen sus vidas, simultáneamente imbricadas en más de una sociedad" (Caglar 2001, citado por PARELLA, 2007, p.158). Si bien actualmente no se puede hablar de la novedad del enfoque, no podemos dejar de resaltar la importancia que aun tiene para captar el fenómeno migratorio de una forma global, amplia, abarcando todos los involucrados, especialmente en la actualidad que la crisis se ha instalado en Portugal, provocando el retorno de muchos brasileños a su país, generando nuevas fracturas espaciales y nuevas incertidumbres en las sociedades de origen y destino (PADILLA y ORTIZ, 2012). 


\title{
Migrar es cambiar...
}

La migración se han convertido en un fenómeno común de nuestro tiempo, y supone cambios en la vida de las personas que se constatan en las diferentes esferas de sus vidas, y van desde lo muy personal e íntimo, hasta aspectos más generales de la esfera laboral y social, aunque en la realidad todos ellos se influencien mutuamente. Por ello,

\begin{abstract}
"El modo como las familias son transformadas, tanto en sus dinámicas como en sus interacciones, a consecuencia de su imbricación en procesos migratorios puede dar lugar a vínculos afectivos y de cuidado de carácter transnacional como estrategia colectiva para hacer frente a las necesidades de supervivencia que alteran y modifican la atención diaria psicológica, emocional y física a las personas." (PARELLA, 2007, p.155).
\end{abstract}

En consecuencia, para analizar en detalle algunas de las transformaciones que los/las inmigrantes sufren, sugiero dividirlos analíticamente en cambios psicosociales, y cambios identitarios que incluyen a su vez cambios en la identidad nacional y étnica, profesional y de género.

\section{a-) Cambios psicosociales}

El cambio de hábitat y la movilidad internacional significan transformaciones, estrés y adaptación a un nuevo ambiente, costumbres, comida, cultura, horarios y sistemas de vida (AKHTAR, 1999; WARD y STYLES, 2003; ARONOWITZ, 1984; YING, 2001). Con el tiempo el acostumbramiento y la adaptación pueden o no, convertirse en integración. Según Akhtar (1999, p.123),

"La migración de un país a otro envuelve pérdidas profundas. Se abandonan las comidas conocidas, la música nativa, las costumbres sociales incuestionables, la historia conocida, y muchas veces el tipo de vestimenta e idioma, mientras que el individuo se enfrenta con comidas de sabor extraño, música diferente, nuevas preocupaciones políticas, un 
idioma complicado, festivales poco animados, una historia desconocida y un ambiente visual desconocido."

Estas pérdidas llevan a que los inmigrantes sufran nostalgia, sintiendo falta o extrañando al país de origen, que incluye desde la familia, las costumbres, las comidas y las amistades, hasta el barrio, los olores y los ruidos, en fin, y todo lo conocido. Esta nostalgia, o saudades, son parte del cotidiano de los inmigrantes brasileños en Portugal, quienes independientemente de su nivel de adaptación o integración, sienten "saudades" de Brasil, ya sea del Brasil como país de nacimiento, pero sobre todo del Brasil particular donde crecieron, vivieron y desarrollaron rutinas, representado por la familia y amigos que dejaron allá, especialmente los que dejaron hijos, pero también por otras envolventes espaciales como la ciudad, el barrio y el paisaje. La nostalgia es descripta por Akhtar como un placer agridulce, una mezcla de dolor y alegría. Para el autor el dolor evoca la separación de los objetos, ahora idealizados, que dejaron atrás, y la felicidad evoca la fantasía de la posible reunión con dicho objetos en un futuro. Los testimonios de los brasileños ilustran tanto el dolor como la felicidad.

El dolor por la separación de objetos, apareció en varios testimonios, pero el más representativo y simbólico fue el momento de mi despedida de los brasileños residentes en el barrio popular de Lisboa donde tuvo lugar una parte de la etnografía multisituada. Todos me abrazaron, pidiendo que aprovechara por ellos, que viviera todo lo que ellos no podían vivir por estar lejos. Todos me desearon buena suerte y muchos éxitos y en la medida que les fue posible, los brasileños de Lisboa se esforzaron para que sus familias me recibieran de brazos abiertos, inclusivamente, una vez que perdieron la vergüenza o timidez, querían que me alojara en sus casas, para poder "vivenciar" más de cerca su tierra roja, el tereré, el chimarrão, los churrascos, la mandioca amarilla, el chuchu, las frutas fantásticas, y especialmente, el cariño de sus seres queridos, conociendo a los hijos/as, los padres, madres, hermanos/as y otros familiares que quedaron en Brasil. Cuando al volver, mostré las fotografías, lágrimas invadieron los ojos de muchos, especialmente de quienes dejaron atrás descendencia, y que todavía viven el dolor de la separación. 
Evocando la llegada y primeros tiempos en Portugal, los inmigrantes cuentan que pasaron momentos muy difíciles y recuerdan llorar o querer llorar, pensando en esa separación con los seres y objetos queridos. Copelito, que cuando llegó era un adulto de más de 40 años, sufrió varios y sucesivos engaños, robos y estafas de dinero, por lo que en algunos momentos de desesperación recuerda llamar a su hermana, en Brasil, llorando como un niño, sin saber que hacer. En su caso, antes de la llegada del resto de la familia, no tenía ningún apoyo en Portugal, vivía en pensiones y con el dinero que trajo desde Brasil, que es su mayoría había perdido en los sucesivos engaños y robos. El caso de Rogelio no fue muy diferente, aun contando con apoyo, ya que llegó con 18 años con una estructura familiar instalada en Lisboa, integrada por hermanos y cuñados, sin embargo Iloró desconsoladamente los primeros meses. No obstante, no todos consiguen superar la transición de cambios lejos de la familia, por ello Rodrigo, quien fue recibido por la suegra, no consiguió adaptarse y después de llorar todos los días porque extrañaba a su hijo y gastó fortunas en llamadas telefónicas que no podía pagar, en un período de tres meses, volvió a Brasil.

Por otro lado, la felicidad que hace parte de la paradoja mencionada por Akhtar, se materializa en la posibilidad y deseo de volver al lugar de origen en un futuro, próximo o lejano. Danieli, de Curitiba, confesó: “Amo a mi país. Estamos acá por motivos económicos y por las ganancias, pero jamás cambiaría a Brasil por cualquier otro país, jamás". La alegría es parte intrínseca de la definición de Brasil para los brasileños, así Andrea, una cearense, dijo "el Brasil es fiesta, es sol, es mar y todo. Brasil tiene muchas cosas lindas, y siento falta de mi país, a pesar de que estoy bien aquí y continuo ayudando a mi familia." Susana, de Paraná, comentó, “para mí Brasil es un arco iris”. Casi todos abrazan la idea de volver al país de origen, aunque no sepan cuando, y se sienten orgullosos de ser brasileños, el sólo hecho de pensar en su país les ilumina la expresión de la cara. La felicidad del encuentro con el país añorado, la familia y seres queridos, es lo que mantiene "vivo" a muchos, aunque sepan que el regreso no sea inmediato, sino diferido hasta que logren los objetivos por los vinieron, generalmente de tipo material y financiero, pero también de otra naturaleza. Sin embargo, en la mayoría de los casos la vuelta se dilata por circunstancias específicas, a-) cuando el inmigrante no ha tenido el 
éxito esperado y piensa que en breve la situación mejorará y salvará la inversión inicial realizada (inversión económica y emocional), o b-) cuando el inmigrante ha conseguido los objetivos, pero todavía quiere mejorar las oportunidades vinculadas al retorno, al reconocer que cuando esto suceda, no conseguirá ayudar a la familia, ya que aunque trabaje en el mismo rubro, la forma como el salario rinde en Brasil es diferente.

Los objetos queridos "perdidos" que producen "saudades" que Akhtar menciona pueden ser identificados también en los objetos que los brasileños me encomendaron, siendo de tipos muy diversos, y van desde la yerba mate (erva) típica de los brasileños de Mato Grosso do Sul para el mate y especialmente para el tereré, los palmitos, los miojos (espagueti seco con sabores), hasta algunos artículos de perfumería como desodorante, aceite para alisar el cabello, entre otras cosas. Algunos de estos pedidos ilustran claramente las características regionales de la inmigración brasileña, ya que el mate y el tereré no son típicos de todos los estados brasileños. Algunos objetos "queridos" son también más añorados por las mujeres, especialmente los artículos de belleza y las marcas preferidas.

Conjuntamente con esta sensación agridulce o la paradoja de dolor y alegría que describe Akhtar, existe otro sentimiento que no aparece en esta tipología, y es un sentimiento de confusión, hibridismo, o de estar en el limbo, que puede compararse con una categoría que Ward y Styles (2003, p.357) mencionan al hablar de la reinvención del yo después de la inmigración. Las autoras hablan del sentido de la pertenencia al nuevo país, y ofrecen 5 categorías, que van desde la pertenencia positiva a la pertenencia negativa, pasando por categorías transitivas (una positiva y otra negativa) y una de limbo. La categoría de pertenencia al limbo, caracteriza a las personas que "viven entre los lugares y que no pertenecen a ningún lugar”. Si bien esta categoría no pueda ser utilizada en todos los casos, propongo utilizarla en aquellos brasileños y brasileñas que han tenido la oportunidad ir y venir, visitando el país de origen y regresando a Portugal, ya que todas ellas confesaron haber experimentado un sentimiento simultáneo de dupla pertenencia y de no pertenencia a ningún lugar. Gisele, una joven de Goiania que lleva 4 años en Portugal dijo, "estoy habituada, acostumbrada a vivir en Portugal. Estuve estos días pasados en Brasil y me moría de nostalgia (saudades) de aquí (Portugal). Y ahora que 
estoy aquí, no pienso volver tan rápido para Brasil." Igualmente, Andrea que vive en Lisboa desde 2003, dijo que se moría de ganas de ir a Brasil y cuando fue, le dieron ganas de estar nuevamente en Portugal, porque es en Portugal donde tiene un rinconcito que siente como propio. Por otro lado, Carlos, un inmigrante de Mato Grosso do Sul que lleva 5 años en Portugal ya no sabe si se considera brasileño o portugués, o nada, a lo que agregó "si voy a Brasil hoy, ya hay cosas de Brasil que me irritan totalmente, o hay cosas que antes no me molestaban y ahora me molestan".

Varios autores mencionan la importancia de la sociabilidad en la integración y/o adaptación de los inmigrantes, y la diversidad de esferas donde dicha sociabilidad ocurre: las redes sociales, la iglesia, el trabajo, los círculos de amistades, etc. (MORALES y FIGUEROA, 2004; ALMEIDA, 2004; PADILLA, 2006a). Esta cuestión emergió en las entrevistas cuando los entrevistados se refirieron a los aspectos emocionales y cambios que han vivido desde la llegada a Portugal en la forma de socializar. La mayoría, tanto hombres como mujeres, dicen haber sufrido cambios emocionales profundos desde que llegaron. De los 40 entrevistados, sólo 6 expresaron no haber sufrido cambios, aunque algunos de ellos en sus narrativas posteriores reconocen transformaciones, sobre todo en la forma de relacionarse e interactuar con los otros.

En consecuencia, las sociabilidades y formas de socialización fueron identificadas como relevantes. Mantener las viejas formas de sociabilidad o aprender nuevas fue una disyuntiva que muchos de los inmigrantes enfrentaron y que son clave para su bienestar en la esfera psicosocial. Por eso, además de considerar dichos cambios, es importante analizarlos a la luz de las redes sociales en las que participan, especialmente si reconocemos que ellas cumplen funciones fundamentales en la adaptación y transición, prestándoles apoyo emocional y de otros tipos cuando es necesario. Repasemos entonces, cuales fueron los principales cambios psicosociales o de comportamiento en la convivencia social mencionados, cuales han sido algunas de las redes sociales de apoyo y si los/las inmigrantes entrevistados se sienten adaptadas.

La mayoría afirma que tanto su personalidad y como su emocional sufrieron alteraciones. Los cambios incluyen el volverse más cerrados, más tímidos, sentirse solos, sentir la falta de libertad o el miedo cuando no están legalizados, ser más duros y menos 
sensibles a ciertas cuestiones, compartir menos, sonreír menos, ser mas introvertidos, no saber qué hacer o estar desesperados. Los siguientes testimonios resumen la experiencia y los cambios.

María, una carioca con 4 años de estadía, contó que fue muy difícil el proceso de transformación y que en un momento dado estaba tan avasallada y era tal el rechazo que sentía hacia la sociedad de acogimiento, que no conseguía escuchar el acento portugués luso. Rosana quien dejó una hija en Brasil y llegó en 2003, confesó que en Portugal la soledad golpea fuerte, las personas no conversan, son muy serias, solo miran el reloj y fuman, y por otro lado las personas están siempre esperando que ella, como brasileña, les trasmita alegría y les cuente historias desde atrás del mostrador del café donde trabaja, de cierto modo cumpliendo el papel de entertainment (MACHADO2003) o de alegría (FERNANDES, 2008). Sin embargo, Rosana no se resigna a llorar sola, y dice que si le dan ganas de llorar, llora en público. Sus propias palabras elucidan mejor, "así como a ellos (portugueses) les gusta verme contenta y contando historias y chistes, pues que me vean triste si estoy triste." Carlos dice que en Portugal él aprendió a ponerse máscaras; los diferentes círculos sociales donde él interactúa, piden y exigen diferentes estados de ánimo, por lo que adoptó una máscara para el trabajo, otra para los amigos del trabajo, otra para los amigos de las salidas nocturnas, una muy diferente para las familias de los amigos, y todavía otra más para el barcito de confianza, además nota que su comportamiento siempre tiene que estar "medido y calculado", y que no se puede hablar con toda la gente. Claudio, que llevaba dos años en Portugal, resume de forma magistral la nueva situación que enfrenta al decir que "quien está fuera de su país, no tiene amigos aquí, su infancia no está aquí, lo que significa que su historia no está aquí. Creo que nos sentimos más debilitados, los brasileños que venimos para Portugal quedamos más fragilizados emocionalmente porque los brasileños sufren presiones por causa del trabajo, por causa de no tener un lugar donde vivir, etc.". Claudia, una mineira que está en Portugal desde 2001, dice que quiera o no quiera, los brasileños tienen que cambiar, porque se deben adaptar y aprender a convivir con personas diferentes. Según ella las personas en Brasil y en Portugal son diferentes, y se comportan de forma muy diferente en el lugar de trabajo, mientras en Brasil la persona trabaja y nadie grita, aquí los patrones 
portugueses gritan mucho y sin mayores alternativas los brasileños acaban por "aguantar muchas situaciones insoportables! (engolir muitos sapos!)"

Si bien estos testimonios no son historias de personas enfermas o con patologías, los sentimientos que describen en relación a la migración coinciden exactamente con los que los psiquiatras Ilaman los estresores que relacionan al llamado Síndrome de Ulises. Achotegui (2004) dice que los estresores (elementos que provocan estrés) son la soledad, el duelo por el fracaso del proyecto migratorio, la lucha por la supervivencia y el miedo, por lo que los elementos generadores de estrés son comunes a todos los inmigrantes en lo cotidiano. Sin patologizar la migración, no todos los inmigrantes entran en depresión, debemos reconocer que a muchos de ellos, sus capacidades de respuesta les permiten conllevar de forma positiva la experiencia migratoria. Sin embargo, los aspectos vinculados a los cambios emocionales y psicosociales deben ser una preocupación tanto para los investigadores como para quienes diseñan las políticas migratorias para considerar el bienestar de los inmigrantes como un aspecto central en su inserción.

Por otro lado, muchos brasileños y brasileñas, a pesar de las presiones y sufrimientos, también reconocen aspectos positivos de los cambios que deben asumir. Así el haber superado el proceso de adaptación, puede traer beneficios al inmigrante. Ward y Styles (2003) en relación a las inmigrantes europeas en Australia, describen la nueva identidad por ellas desarrolladas con rasgos positivos como ser una nueva persona, ser más seguras, más independientes y fuertes. De forma semejante, algunos inmigrantes brasileños y brasileñas, reconocen haber crecido y madurado con la inmigración, y haber aprendido a hacer cosas por sí mismo, especialmente algunas brasileñas que emigraron como forma de superar o huir de relaciones fracasadas, y actualmente han tomado las riendas de sus vidas.

Uno de los temas relevantes en relación a los aspectos psicosociales, tiene que ver con la esfera de la sociabilidad porque indica con quien el inmigrante pasa tiempo libre, con quien conversa y comparte, con quien se divierte y a quien le cuenta sus secretos, además de permitirnos identificar sus redes sociales. Si bien sabemos que muchos brasileños tienen tanto amigos de su misma nacionalidad como portugueses (PADILLA, 
2004b), dependiendo muchas veces de la socialización laboral, que varía según su posición en el mercado de trabajo segmentado por género y grupo étnico, en general se sienten más a gusto entre los círculos de amistades compuesto mayoritariamente por coétnicos. Inclusivamente muchas veces los círculos de amistades de los brasileños se limitan a quienes son del mismo lugar de origen en Brasil.

En el barrio popular de Lisboa estudiado, donde no residen única ni predominantemente inmigrantes, los brasileños se conocen entre ellos, sin embargo las relaciones de proximidad y amistad más estrechas se verifican entre los originarios de la misma región, como el caso de los provenientes de Dourados-Itaporã. Así, las redes, preexistentes a la migración, ayudan y dan la bienvenida a los recién llegados, reencaminando sus amistades y círculos de interacción social, aunque los inmigrantes no se conociesen antes de la partida, ya que existe siempre algún familiar cercano o lejano o algún amigo en el origen que conoce a alguien en el destino, y así las redes se entrelazan, reforzando los ámbitos de sociabilidad basados en referencias “transnacionales” y locales comunes, que permiten identificar la categoría "translocal". Por ejemplo Juliana y Andrea, las hermanas de Dourados, llegaron a casa de unos primos lejanos de unos familiares de Itaporã, a quienes no conocían. De a poco encontraron trabajo y recomenzaron sus vidas, aunque continuaron muy ligadas a esa primera experiencia de acogimiento. Posteriormente, Juliana se vinculó sentimentalmente a una de las personas que la acogieron, motivo que la lleva a mantener secreta la relación a su familia en Brasil, para evitar ser juzgada y controlada. Andrea, por su lado, regresó a Brasil con su novio, primo del novio de Juliana, a quien también conoció en Lisboa, aunque proviene de la misma ciudad. La categoría de translocalismo resulta útil para ilustrar la conjunción entre lo local y lo transnacional en este tipo de relaciones y situaciones, si aceptamos la definición de translocalidad como el espacio en el cual nuevas formas de identidades post-nacionales se construyen" (MANDEVILLE, 2002, p.204). 


\section{b-) Cambios identitarios}

Ying (2001, p.411) sostiene que "la migración supone un desafío intrapsíquico de separación-individualización" que lleva a que los inmigrantes desarrollen una nueva identidad en el país de destino. Vertovec (2001: 573) define identidad como "las formas en que las personas se ven a sí mismo y como los otros los caracterizan", tal como Goffman (1969) había sugerido. Esta definición es importante porque reconoce el sentido bidireccional de la formación de una identidad, al no sólo depender de quien la asume sino también de cómo es modelada y percibida por otros, en este caso, por la sociedad de destino. Asimismo, las identidades culturales están influenciadas "por un número de factores - 'raza', etnicidad, género y clase por mencionar algunos; aunque el verdadero locus de dichos factores, sea la noción de diferencia" (CLARKE, 2008, p.510), en la que la sociedad de destino juega un papel importante, generalmente a través de la creación y reproducción de estereotipos, imaginarios y estigmatizaciones.

Como mencionado, muchos de los cambios sufridos por los inmigrantes se relacionan con la personalidad, el comportamiento y la (re)socialización, que llevan a la definición de un nuevo "yo", y a asumir una o varias nuevas identidades. En este sentido, Akhtar (1999) alerta que la inmigración es un complejo proceso psicosocial con efectos duraderos sobre la identidad individual de las personas, y una vez que se supera el choque cultural inicial, emergen nuevas identidades, algunas de las cuales, híbridas. Así podemos adelantar que las nuevas identidades de los/las inmigrantes brasileños/as se desarrollan de forma diferente en los varios ámbitos donde interactúan.

Por un lado, la llegada a un nuevo país implica que por primera vez los recién llegados se cuestionen lo que realmente es ser brasileño, ya que dentro del país de origen la tensión se producía entre otras identidades, ya sea raciales, regionales, de género, de clase, entre otras. La identidad nacional, como todas las identidades es relacional, y por ello se define y exacerba en relación a otras, en este caso, la de ser brasileño/a. Así la identidad brasileña se define a partir de la interacción con otros brasileños, con los portugueses y con otros inmigrantes, además no es estanque, sino que puede ser reformulada o transformada a lo largo del tiempo, según la posición en el país de destino, y según se vuelva o no al país de origen (ver Figura 2). Las identidades regionales 
relacionadas con las zonas de origen en Brasil ganan relevancia en la socialización entre brasileños, ya que las constelaciones identitarias se configuran siguiendo otras lógicas, incorporando las diferencias de prácticas culturales regionales. Sin embargo, conviene resaltar que en Portugal la identidad nacional de los brasileños gana el calificativo de identidad étnico-nacional y se vuelve la identidad predominante.

Figura 2. Factores que contribuyen en la formación de la Identidad Brasileña

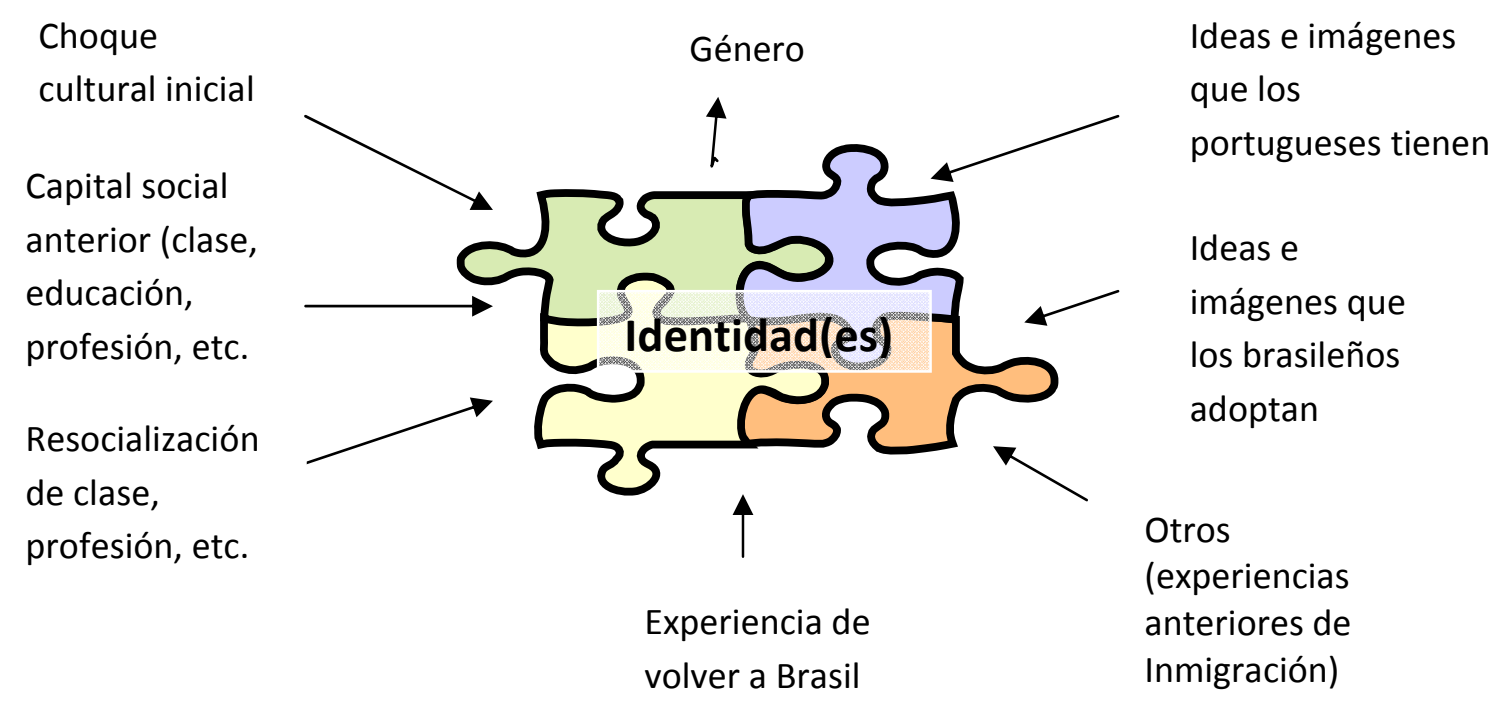

Cuando confrontados con la pregunta sobre qué significa ser "brasileño o brasileña", la palabra más utilizada fue la de orgullo, para la mayoría es sinónimo de alegría, felicidad, satisfacción. De los 40 entrevistados, solo uno se refirió a ser brasileño con palabras negativas: "Para mí es una fatalidad haber nacido allá, haberme educado allá y haber adquirido los valores culturales allá". Sin embargo si analizamos sus palabras encuadrándolas su respuesta en su historia de vida, esta reacción adquiere otro sentido, al tratarse de un brasileño exiliado, llegado a Portugal en 1974, durante la dictadura militar brasileña, y a pesar de esa respuesta, era miembro activo en la comunidad brasileña. Según Akhtar (1999, p.124), los sentimientos que desarrollan los exiliados son diferentes de los de otros inmigrantes, ya que sufren de un tipo particular de bloqueo emocional que nos les permite sentir nostalgia, por haber abandonado el país de 
nacimiento en contra de su deseo. Por ello suele ser común que los exiliados, a diferencia de los inmigrantes, no idealicen el lugar de origen y muchas veces no quieran volver.

Si nos enfocamos en los casos que identificaron Brasil (o la brasilidad) con un sentimiento de orgullo, de satisfacción, de un "estado de espíritu”, arribamos también a una paradoja, ya que por un lado los inmigrantes están muy orgullosos de su Brasil, pero por el otro, lo dejaron porque no les brindaba oportunidades de una vida digna. Varios entrevistados manifestaron que por más que se trabaje mucho no es posible tener acceso a los bienes añorados como una casa, un auto, electrodomésticos, ni de vestirse bien y estudiar. Por lo que esa identidad brasileña se basa, por un lado, en orgullo y sentido de patriotismo, pero por el otro asume resentimiento por haber tenido que partir. Esta paradoja se repite en otros sentidos y ámbitos, ya que si bien expresan sentimientos positivos sobre la identidad nacional, en muchas circunstancias no quieren ser identificados como brasileños, prefiriendo pasar desapercibidos en la sociedad de recepción. Esto se debe a la imagen negativa que los portugueses tienen de los brasileños. Estudios indican que los portugueses creen que los brasileños trabajan poco, menos que los portugueses y que los inmigrantes provenientes de África y de Europa del Este. Asimismo, estos estudios afirman que las brasileñas han contribuido al aumento de la prostitución (LAGES y POLICARPO, 2003; LAGES, 2006).

Si a esto agregamos que muchos brasileños e brasileñas interiorizan algunos de estos prejuicios, no debe sorprendernos que se traduzca en una situación de rechazo a ser identificado como brasileño o brasileña, generando un sentido de enajenación. Si bien no hay una única tendencia, hay indicios de tres posiciones más comunes, aquéllos que reproducen y refuerzan los estereotipos sobre ellos mismos, aquéllos que los ignoran, y otros que los combaten, interpretándolo como una situación de competencia.

Así, a muchos brasileños y brasileñas, a nivel individual, no les gusta ser identificados como tales y prefieren no relacionarse o evitar las relaciones evidentes con sus coétnicos, criticándolos por sus 'comportamientos vergonzosos como beber mucho, hablar muy alto, llamar la atención en público'. Tanto Paulo como Viviane (ambos de Minas Gerais) confesaron que no les gusta ir a los lugares frecuentado por brasileños, y que prefieren ‘mezclarse’ con portugueses. Leandro agregó que ya no va a lugares donde 
se reúnen los brasileños porque 'estando acá, deberían comportarse de otra manera, diferente', asumiendo que la conducta de sus compatriotas deja mucho que desear.

Estos brasileños muchas veces reniegan de su identidad, e intentan mostrar que no pertenecen a "esa clase de brasileños". En otras palabras, una parte de la identidad nacional brasileña en Portugal se basa en un sentimiento de vergüenza, por lo que luchan por definirse como diferentes, como siendo un/a brasileño/a que no reúne los requisitos que generalmente les son atribuidos: fiestero, bebedor, poco trabajador, mentiroso, etc., y en cambio ser un brasileño/a que no parece serlo por ser serio, trabajador, honrado, entre otras cosas, que quiere 'pasar' desapercibido como si fuera portugués. Magda, una mineira, piensa que son los propios brasileños los que contribuyen a que los portugueses los discriminen por la forma de estar en la sociedad, y Andrea Luís, pernambucano, cree que se debe a que algún brasileño haya hecho algo mal. Estas experiencias, manifestada por muchos entrevistados, ilustra la culpabilización de la víctima y la interiorización de las ideas y estereotipos vigentes sobre los brasileños en Portugal, que como se explicará adquiere un sentido específico en el caso de las mujeres. Sin embargo, esta situación es paradoxal, ya que los círculos de amigos de la mayoría de los inmigrantes entrevistados están compuestos por brasileños y/o también portugueses.

Esta veta negativa de la identidad brasileña, se mezcla con otra imagen estereotipada que existe en Portugal, y en varios países del Norte, sobre los inmigrantes: la imagen del inmigrante como pobre. Es común que la sociedad de acogimiento desconozca la realidad concreta del país de origen de los inmigrantes así como también la realidad específica del inmigrante, y equipare al inmigrante con el pobre (PADILLA, 2004a, 2006a). En nuestras charlas, Regina comentó varias veces, que si bien ellos salieron de Brasil para buscar un futuro mejor, no eran miserables ni vivían en las favelas, pero que nadie entiende eso, sin importar cuantas veces lo expliquen. Varios entrevistados mencionan que siempre son percibidos como pobres, y una vez en Portugal son etiquetados como tales y no tienen forma de cambiar esa estigmatización. En consecuencia, los inmigrantes brasileños deben asumir una identidad de clase que muchos no tenían en Brasil. Esto es así tanto para los brasileños de clase media como los de clase media baja, quienes nunca antes se vieron a sí mismos como pobres. Ellos 
argumentan que "en Brasil nunca nos faltó la comida, no somos pobres", pero una vez en Portugal, no tienen como escapar a la asociación con destitución, pobreza y necesidad. Como dice Mendes (2000, p.3), el sujeto social es portador de diferentes identidades individual, de clase, nacional, profesional, étnica, etc. y según sea la ocasión y el momento, cada una de ellas se hace más o menos relevante, aunque cuando la persona es identificada como inmigrante de un país más pobre, dicha identidad sobresale y las otras se vuelven secundarias. En este caso, los inmigrantes no tienen la libertad de elegir su identidad, por lo que es necesario que los estudios consideren cuidadosamente la construcción y percepción de la imaginación y emoción humana (CLARKE, 2008, p.528) en las cuales la identidad ocupa un lugar fundamental. Por otro lado, los aspectos transnacionales propios de la inmigración significan un desafío a las teorías de clase, generalmente concebidas para sociedades cerradas y homogéneas.

Según Kearney y Beserra (2004, p.3-4) "la clase es una identidad asociada con un grupo ocupacional o económico (i.e. la clase trabajadora, la clase media), un estrato social y económico con características más o menos distintivas, cuyos miembros pueden o no tener un sentimiento de identidad colectiva." Si bien algunos piensan que la identidad de clase desaparece o es menos importante que la identidad nacional, étnica, de género u otra, esto no es verdad, no puede darse como un dato adquirido porque los modos en que entendemos las identidades, incluyendo la clase social, varían según los contextos. En un contexto globalizado, con un mundo estratificado en países ricos y pobres, muchas veces la definición de clase no se realiza a título individual, ya que desde una perspectiva transnacional, los países están posicionados jerárquicamente, existiendo una dialéctica entre ellos. Según estos autores

"la dinámica de las identidades de clase se vuelve más compleja y sutil al tiempo que los migrantes entran y salen de múltiples espacios socioeconómicos que llevan a unidades socioeconómicas básicas (comunidades, familias, hogares, etc.) a atravesar complejos procesos internos de diferenciación y diversificación" (KEARNEY y BESERRA, 2004, p.7). 
En este sentido, no podemos olvidar que la estrategia de inmigración es en sí misma una estrategia de clase, siendo que la inmigración de los brasileños es, en su generalidad aunque con muchas excepciones y complementariedades, una inmigración económica. Las narrativas de los entrevistados relacionan sus proyectos de migración con intentos para conseguir un mejor reposicionamiento tanto en la esfera nacional en el país de origen, como en el mercado internacional, en el país de destino. Esto explica que un inmigrante deje su trabajo de maestro mayor de obra en su país de origen, para ser un simple albañil en Portugal, sabiendo que el valor del salario le compensará aquella pérdida inicial (y tal vez permanente) de estatus laboral.

Sin embargo las estrategias de clase a veces se confunden o mezclan con otras estrategias (de pareja, de movilidad, de independencia y autoestima). Una profesora de educación física, con muchos años de antigüedad y estabilidad en el trabajo, se convierte en empleada doméstica para poder vivir al lado de su compañero con quien no podría estar en el país de origen por ser divorciado, mientras ahorra y se forja una vida mejor. Asimismo, una ama de casa se convierte en empleada doméstica porque esta oportunidad la recompensa económica y materialmente, proporcionándole ventajas y un mejor reposicionamiento cuando regrese a su país natal. En el caso de las amas de casa que nunca trabajaron, tienen la posibilidad de recibir un sueldo por algo que antes hacían sin remuneración, mientras que simultáneamente les permite obtener poder de negociación con sus parejas. Regina, desde que se casó, no había trabajado fuera de casa, por lo que no contribuía financieramente en el sustento de hijos o de su madre. En Portugal ideó una estrategia de inserción laboral que le permite trabajar en casa y ganar dinero, cuidando los niños de las brasileñas conocidas que trabajan, cuidando de la casa no sólo para la familia sino para otros huéspedes que alquilan los restantes cuartos del apartamento donde viven, haciendo la limpieza, la comida, lavando y planchando la ropa de todos, lo que le asegura rendimientos considerables a fin de mes. De esta forma, ella contribuye en el proyecto migratorio familiar, y todavía ayuda a su madre que quedó en Mato Grosso do Sul. Al momento de la entrevista, el marido de Regina quería regresar a Brasil, pero ella había decidido permanecer unos años más, porque está consciente de que una vez que regresen, la actividad que realiza en Portugal pierde sentido en Brasil, y 
perderá así oportunidad de contribuir en el presupuesto familiar, perdiendo influencia y poder en las decisiones familiares.

Las estrategias de inserción laboral mencionadas están asociadas a estrategias de clase que suponen una resocialización de clase. Mientras en el país de destino se vive una resocialización descendente por ser inmigrantes y ser vistos como pobres, en la eventualidad de regreso al país de origen, la resocialización esperada es ascendente, y la nueva clase social (esperada) les permitirá tener acceso a amenidades que antes no poseían, como por ejemplo casa, auto, muebles, electrodomésticos, otras propiedades, o negocio propio, entre varias alternativas posibles, como fue el caso de Andrea al regresar a Dourados, que se desempeño como empleada doméstica interna y con sacrificio ahorró suficiente para comenzar nuevamente en su tierra natal.

Parte de esta identidad de clase, está relacionada también con la identidad laboralprofesional, que igualmente sufre una alteración en contexto migratorio. Generalmente la nueva identidad profesional, en términos de prestigio, es valorada de forma inferior a la sostenida anteriormente en Brasil, pero se ve compensada en lo material, ya que los salarios son (o eran) comparativamente mejores, al permitirles ahorrar y enviar dinero (PADILLA, 2004a; MARTES 2000). Sin embargo, quienes se han podido establecer como propietarios de negocios o empresarios, si bien se sienten discriminados por ser brasileños, al mismo tiempo tienen un capital social que les permite ser más aceptados. Es el caso de Carlos, arquitecto de Mato Groso do Sul que vivía en São Paulo antes de emigrar, quien es dueño de un bar en Bairro Alto.

Finalmente, otro aspecto de la formación de las identidades brasileñas en Portugal que no puede ignorarse es la identidad de género, que afecta sobre todo a la mujer brasileña. Ser mujer y brasileña marca profundamente la experiencia de inmigración. Si bien la imagen sensual y sexual de la brasileña no es nueva ni novedosa a nivel internacional, teniendo la "marca de la prostitución" (MARGOLIS, 1998; BÓGUS y BASSANESI, 1999, PADILLA, 2004a y 2006a), la brasileña inmigrante promedio desconoce esta situación en general, y se ve forzada a asumir y lidiar con una nueva identidad que tiene una fuerte carga sexual, la que le genera permanentemente situaciones incómodas y de acoso a las que no estaba acostumbrada en Brasil. Por ello, es importante destacar 
que todas las mujeres brasileñas, sean casadas o solteras, jóvenes o maduras, visiblemente ricas o no, por el sólo hecho de ser brasileñas, son vistas como potenciales prostitutas, como mujeres fáciles y/o que vinieron de forma interesada para "cazar y casar" un portugués. Esta realidad produce efectos diferentes en las mujeres yen los hombres, acarreando consecuencias más perjudiciales para ellas. Esto refuerza la construcción de una determinada identidad vinculada a sexualidades específicas, que manipula la normalización o no de dichas sexualidades a través de la moralidad (CLARKE 2008).

En consecuencia, esta situación lleva a los propios brasileños y brasileñas a adoptar una posición generalizada de desconfianza y vigilancia. Las mujeres son observadas con lupa (entre ellas mismas, y por sus compatriotas masculinos), y se cuestiona no sólo el tipo de trabajo que realizan sino también se monitorean sus comportamientos y conductas. En las parejas surge mucho el tema de los celos, vigilándose de cerca como las brasileñas se visten. Los hombres "controlan" a sus mujeres, y ellas, "aseguran" a sus maridos, procediendo a una selección de las amistades porque no quieren ser amigas de aquellas brasileñas provocativas y llamativas. Carolina Así suele producirse una cacería coétnica de brujas.

Por otro lado, el estado de desconfianza y vigilancia se reproduce en las relaciones con los portugueses, afectándolas profundamente. Debido a los estereotipos existentes y al antiguo imaginario colonial que erotiza a la mujer brasileña, asociándola a la sensualidad y promiscuidad (PONTES, 2004; PADILLA 2007; PADILLA, GOMES y FERNANDES 2010; PADILLA y GOMES 2012; GOMES, 2011 y 2013;), los hombres portugueses están inclinados a pensar que las brasileñas son fáciles y disponibles. Las entrevistadas expresaron ser acosadas y malinterpretadas ante cualquier expresión de afecto, por lo que deben estar siempre atentas y controlar su espontaneidad. María, carioca, confesó que se ha vuelto más reprimida, siendo que se le hace difícil dialogar en la convivencia social para no ser malinterpretada.

Las que trabajan en cafés o barcitos manifestaron que deben cuidar el exceso de simpatía en la atención al cliente, y aunque su trabajo sea dar un buen servicio, y suelan ser contratadas por poseer dicha simpatía, así deben "aportuguesarse”, volviéndose más 
antipáticas. La mayoría de las brasileñas lamentan que en cada ocasión que toman un taxi tengan que pasar por situaciones incómodas, ya que los taxistas las asumen como potenciales prostitutas, strippers o bailarina exóticas. Ivânia, de Minas Gerais, relató varias y repetidas experiencias, manifestando que se hace insoportable. Situación que se repitió con casi todas las entrevistadas, provenientes de diferentes regiones de Brasil, de diferentes clases sociales y pertenencias étnico-raciales.

En el caso de las relaciones de las brasileñas con las mujeres portuguesas, la desconfianza es automática, aunque se refleje de forma diferente. Se produce un cierto enfrentamiento entre brasileñas y portuguesas. Las portuguesas suelen sospechar de ellas y las tratan mal. Según los testimonios, las portuguesas las observan cuidadosa y despectivamente de 'arriba para abajo', haciendo un ejercicio de reconocimiento, como pasando revista. Andrea cuenta que las portuguesas tienen la manía de observarlas al milímetro, como si pasasen "revista”, y no entiende por qué; por otro lado reconoce que una de las principales barreras que enfrentó al llegar fue el prejuicio que existe contra la mujer brasileña, que las presionan para que cambien su forma de ser, sus comportamientos y reacciones espontáneas para no ser malinterpretadas. Agregó que si las portuguesas se visten provocativamente, nadie dice nada, pero si son las brasileñas, son juzgadas inmediatamente sin consideración.

Rosana, compartió dos historias que ilustran con claridad lo que sucede en la sociedad portuguesa en relación a las brasileñas. Una de las historias es sobre su amiga y la otra es sobre ella misma. La amiga de Rosana tiene un novio portugués desde hace 4 años, y viven juntos. Ella está legalizada, por lo que no "necesita" del casamiento para regularizar su situación. Decidieron casarse, y los padres del novio reaccionaron muy mal, no dieron la aprobación para el casamiento, oponiéndose. Sin embargo no habían reaccionado negativamente cuando tomaron la decisión de vivir juntos, lo que lleva a pensar que el problema es intentar afianzar la relación, y no la convivencia con la joven brasileña. Justamente, esta fue la reflexión de Rosana, que se cuestionó cuál es el verdadero inconveniente, que sea brasileña. Su segunda historia, es su propia historia. Rosana fue a una repartición pública acompañada de su novio, que es portugués. Allí, su novio se encontró un amigo, y al presentarle a Rosana dijo, "esta es mi novia, es 
brasileña”, y su amigo respondió, "eso no es problema, yo también ya tuve una”. Rosana se sintió insultada y tratada como un objeto, cuestionándose por qué es importante aclarar que es brasileña, como si fuese malo. Para ella ser brasileña en Portugal tiene un sabor amargo propio de la discriminación.

No obstante, no son únicamente las brasileñas que reconocen la valoración negativa que pesa sobre ellas. La mayoría de los hombres entrevistados hizo referencia al prejuicio que existe contra sus compatriotas. Beto, de Santa Catarina, contó "la brasileña tiene fama de ser fácil, por más trabajadora que sea. Por eso yo no dejo que mi hermana venga para acá. Yo sé bien de esto porque en el primer lugar donde viví, sólo había mujeres brasileñas, muy trabajadoras y todas casadas, y desistieron de buscar buenos empleos, porque eran asediadas por los patrones portugueses, sólo por saber que eran brasileñas. También veo cómo los portugueses se vuelven locos por tener un romance con una brasileña. A mí no me gusta nada esta fama que las brasileñas tienen acá."

Jacira, al expresar como se siente como mujer brasileña en Portugal dijo: "lo que siento es una cierta reacción negativa, principalmente contra las mujeres brasileñas, aunque yo sea una. Aquella cosa de que algunas mujeres vienen a Portugal y no desempeñan un papel tan aceptable por la sociedad, y eso causa problemas para todas las mujeres brasileñas. Por eso la mujer siente, de parte de las otras mujeres, una reacción exacerbada de competencia; y por parte de los hombres, ellos esperan que estemos siempre disponibles, y esa sensación es una sensación muy mala. [... ] Las miradas, de las propias mujeres...". Historias de esta naturaleza son numerosas, Jenifer, una mineira que vive en Portugal hace 3 años, manifestó que al ser identificada como brasileña, tanto hombres como mujeres llegan a conclusiones infelices. En su primer empleo como mesera, tuvo que enfrentar situaciones desagradables porque había un portugués que siempre iba y "un día me llamó para que conversáramos y vino con ideas y propuestas raras, yo le conté a mi patrona y ella me dijo que debía continuar siendo simpática con él, porque él tiene mucho dinero y además porque era brasileña... ella me estaba “empujando" encima del portugués. Las personas piensan que como somos brasileños, hacemos cualquier cosa para ganar dinero." 
Analizando en profundidad el atributo de mujer fácil que es atribuido a la mujer brasileña, y teniendo en cuenta que existe una etnicización y exotización de ciertas características de la personalidad que la sociedad portuguesa le asigna a los brasileños, como la simpatía, el buen trato, la alegría, el buen humor, el gusto por las fiestas, etc. (MACHADO, 2003), vemos como esta etnicización afecta de forma diferente a hombres y mujeres, agravando y perjudicando la situación de la brasileña. Por un lado la sociedad espera que ella sea alegre y simpática, pero cuando lo es, la acusa de prostituta, fácil y provocativa. Esta situación contradictoria, crea un escenario de ambigüedad esquizofrénica para las brasileñas, que sienten una enorme presión para ajustarse a dos modelos contradictorios, ser 'buena y mala' mujer al mismo tiempo. La sociedad de destino impone un proceso de resocialización a las brasileñas, que las obliga a transformar su personalidad y su manera de ser, generando una serie de emociones y procesos psicológicos poco estudiados, que derivan en vulnerabilidad y en un tobogán de emociones contradictorias.

\section{Conclusión}

Las narrativas, historias y testimonios compartidos en este trabajo ponen de manifiesto el "peso" que la inmigración tiene sobre las personas, ilustrando los diferentes y múltiples cambios que los inmigrantes deben sufrir y asumir. Muchas de estas transformaciones generan estrés e incertidumbre que permiten identificar la dificultad de los procesos de adaptación. Si bien algunos autores hablan del Síndrome de Ulises, y lo hacen como una patología, la verdad es que el proceso no debe ser patologizado sino que debe ser considerado un proceso de acomodación a la nueva sociedad. Las experiencias migratorias son muy complejas a nivel individual y social, implicando riesgos y amenazas que si no son contenidos y manejador, pueden llevar a situaciones serias, sobre todo a casos de aislamiento y soledad.

Los cambios y transformaciones identificadas van desde aspectos específicos de la personalidad y de los comportamientos, hasta los modos y círculos de sociabilidad, los cuales, como fue detallado, suponen e imponen el desarrollo de nuevas identidades. El 
proceso de formación de identidades, como se ilustró, es complicado y enmarañado, respondiendo a diversas presiones y situaciones. En ese sentido, algunas identidades se vuelven más relevantes que otras, dependiendo del contexto, pero todas exigen mutaciones.

Las narrativas presentadas muestran que las constelaciones identitarias son varias y cambiantes según el plano considerado. Por ellos/as identidades son multidimensionales, resultando de la sobreposición de las diferentes esferas de acción e intervención de los individuos (sociedad, trabajo, sociabilidades, etc.) y por ello las identificaciones con la brasilidad también pueden cambiar según el contexto específico de socialización, Sin embargo las relaciones asimétricas que circundan las relaciones migratorias, en las cuales los inmigrantes tienen menos poder que los ciudadanos nacionales, conlleva a que el brasileño, y sobre todo la brasileña, tengan menos capacidad y libertad para decidir lo que significa e implica ser "inmigrante brasileño/a" en Portugal.

En consecuencia, en el desarrollo de la identidad étnico-nacional (o las identidades étnicas), que supone el desarrollo de sentimientos de pertenencia y de autoestima (MENDES, 2000, p.3), el brasileño no siempre consigue negociar una identidad positiva. Como comprobamos, las identidades brasileñas tiene tanto un lado positivo vinculado al orgullo (en la autoidentificación), pero también tiene una veta negativa vinculada a la vergüenza y a la desvalorización, situación contradictoria provocada por la presión de la sociedad de destino (identificación externa). En este contexto opuesto y ambiguo, los inmigrantes intentan conciliar el "yo/nosotros", con los "otros", y por eso hablan de "esos brasileños y brasileñas" intentando establecer distancia y diferenciación, reconociendo la existencia de 'diferentes tipos de brasileños', e intentando acercarse en la medida de lo posible, a lo normal, que es ser portugués o por lo menos el buen ejemplo de brasileño/a.

El aumento de la inmigración brasileña que ha sido sentida como una 'invasión' en Portugal, no ha llevado necesariamente a la normalización de la presencia brasileña en la sociedad de destino. Sin embargo, la llegada de la crisis y simultáneamente la mejora de la imagen internacional de Brasil como país potencia, está provocando un punto de 
inflexión, que puede ayudar (veremos) a cambiar la situación hasta ahora prevaleciente (PADILLA y ORTIZ, 2012), reduciendo las asimetrías y la brecha en las relaciones de poder.

La clave puede estar en que uno de los temas más presentes en la sociedad portuguesa actual es la emigración y no la inmigración. Este impasse puede implicar un cambio en la percepción de Brasil y de los/las brasileños/as, ayudando a equilibrar la desigualdad que caracterizaba las relaciones entre inmigrantes y nacionales. Por otro lado, en los último años si bien la inmigración brasileña de carácter laboral ha disminuido o desaparecido, los movimientos migratorios que mantienen viva esta corriente es la llegada de estudiantes internacionales de licenciatura, maestría y doctorado, al igual que los post-doctorados y sabáticos, muchos de ellos encuadrados en el programa "Ciencia Sin Fronteras", según se evidencia en las estadísticas oficiales (SEF 2012). En este sentido, las universidades portuguesas ante la disminución del número de matrículas nacionales y de sus presupuestos, buscan activamente como público de atracción a los estudiantes de Brasil y de los países africanos de lengua portuguesa.

Podríamos preguntarnos si la crisis es capaz de producir cambios radicales. Será que la sociedad portuguesa va a modificar la percepción estigmatizadora y generalizada de ver a los brasileños y brasileñas como inmigrantes pobres, confinados a identidades proletarizadas, o si el abanico de identidades e identificaciones se extenderá hacia otras más flexibles y liberadoras que les permita mejorar sus experiencias migratorias. 


\section{Referências}

ACHOTEGUI, Joseba. Emigrar en situación extrema: el Síndrome de inmigrante con estrés crónico y múltiple (Síndrome de Ulises). Norte de Salud Mental, n. 21, p. 39-52, 2004.

AKHTAR, Salman. The immigrant, the exile and the experience of nostalgia. Journal of Applied Psychoanalytic Studies, v.1, n. 2, p.123-130, 1999.

ALMEIDA, Ronaldo de. Religion in the metro area of São Paulo. Revista Brasileira de Ciências Socias, v.19, n. 56, p.15-27, oct., 2004.

ARONOWITZ, Michael. The social and emotional adjustmentof immigrant children: $A$ reviewof the literature. International Migration Review, v. 18, n.2, p. 237-257. Summer, 1984.

BAGANHA, Maria; GÓIS, Pedro. Migrações internacionais de e para Portugal: o que sabemos e para onde vamos?.Revista Crítica de Ciências Sociais, n.52, p. 229- 280, 1999.

BÓGUS, Lúcia; BASSANESI, Silvia. Brasileiros na Itália: movimentos migratórios e inserção social. Margem. São Paulo: PUC-SP, EDUC/FAPESP, v..10, p. 211-227.1999.

BRETTELL, Caroline. Theorizing migration in anthropology. In BRETTELL, Caroline; HOLLIFIELD, James (Eds.). Migration theory. talkingacross disciplines. Routledge: New York, 2000.

CAGLAR, Ayse. Constructing metaphors and the transnationalisation of spaces in Berlin. Journal of Ethnicand Migration Studies, v.27, n.4, p. 601-613, 2001.

CLARKE, Simon. Culture and identity. In: THE SAGE Handbook of Cultural Analysis. SAGE Publications, 2008, p. 510-529. Disponível em <http://www.sage-

ereference.com/view/hdbk_culturanalysis/n24.xml>. Acesso em 3/3/2014.

ESCUDERO, Margarita. Exploración del síndrome de estrés crónico ‘Síndrome de Ulises' en inmigrantes de origen argentino. Nure Investigación, n.8, Sep.2004. Disponível em <http://www.carm.es/ctra/cendoc/doc-pdf/Pub/pub-0029.pdf>. Acesso em 2/10/2013.

FERNANDES, Gleiciani. Viver além-mar: estrutura e experiência de brasileiras imigrantes na região metropolitana de Lisboa. Tese (Maestría en Antropología) - Instituto de Ciências Sociais da Universidade de Lisboa, Lisboa, 2008.

GAILLY, Antoine. La atención sensible a la cultura. In COMELLES, Josep; ALLUÉ, Xavier; BERNAL, Mariola; FERNÁNDEZ-RUFETE, José y MASCARELLA, Laura (Comps.). Migraciones y salud. Tarragona: URV, 2010, p.17-54.

GLICK-SCHILLER, Nina; BASCH, Linda; BLANC-SZANTON, Cristina. Towards a definition of Transnationalisms. Introductory Remarks and Research Questions. In GLICK-SCHILLER, Nina; BASCH, Linda y BLANC-SZANTON, Cristina (Comps.), Toward a transnational perspective of migration, race, class, ethnicity and nationalism reconsidered. New York: 
New York Academy of Sciences, 1992, p. 1-24.

GOFFMAN, Edwin. The presentationof self in everyday life. London: Penguin, 1969.

GOMES, Mariana Selister. Mulheres brasileiras em Portugal e imaginários sociais: uma revisão crítica da literatura. CIES e-Working Paper. Lisboa : Centro de Investigação e Estudos deSociologia, Instituto Universitário de Lisboa, n. 206, 2011 Disponível em <http://www.cies.iscte.pt/destaques/documents/CIES-WP106_Gomes.pdf>. Acesso em 2/10/2013.

GOMES, Mariana Selister. . O Imaginário Socialmulher brasileira em Portugal: uma análise da construção de saberes, das relações de poder e dos modos de subjetivação.2013.Tese (Doutoramento em Sociologia) - Lisboa, ISCTE-IUL,2013.

GÓIS, Pedro; MARQUES, Jose Carlos; PADILLA, Beatriz; PEIXOTO, João. Segunda ou terceira vaga? As características da imigracão brasileira recente em Portugal. Migrações, n.5, p.111-133. 2009.

KEARNEY, Michael; BESERRA, Bernardete. Migration and identities: a classbasedapproach. Latin American Perspectives, Sigue 138, v.31 n. 5, p. 3-14, 2004.

LACOMBA, Joan. Teorías y prácticas de la inmigración: de los modelos explicativos a los relatos y proyectos migratorios. Scripta Nova Revista Electrónica de Geografía y Ciencias Sociales, n.94 (11), p. 00-00. 2001.

LAGES, Mário; POLICARPO, Vera. Atitudes e valores perante a imigração. Lisboa: Observatório da Imigração/ACIME, 2003.

LAGES, Mário (Coord.). Os imigrantes e a população portuguesa: imagens recíprocas, análise de duas sondagens. Lisboa: Observatório da Imigração/ACIME, 2006.

LESSINGER, Johanna. From the Ganges to the Hudson: Indian immigrants in New York City. Boston: Allynand Bacon, 1995.

LURBE i PUERTO, Kàtia Inmigrantes como grupo de riesgo sanitario: instrumentalizar el riesgo ¿inserta o segrega?. In COMELLES, Josep, ALLUE, Xavier, BERNAL, Mariola, FERNANDEZ-RUFETE, José y MASCARELLA, Laura (Comps) Migraciones y salud.

Tarragoan: URV, 2009, p 55-70.

MACHADO, Igor. Cárcere público processos de exotização entre imigrantes brasileiros no Porto, Portugal.2003. Tese (Doutorado em Antropologia) - Universidade Estadual de Campinas, Campinas, 2003.

MANDAVILLE, Peter. Reading the state from elsewhere: towards an anthropology of the postnational. Review of International Studies, v.28. n. 01, p. 199-207, 2002. 
MARGOLIS, Maxine. Transnationalism and popular culture: the case of Brazilian immigrants in the United States. Journal of Popular Culture. v.29, p.29-41, 1995.

MARGOLIS, Maxine. An Invisible minority. Brazilians in New York City. Boston: Allyn \& Bacon, 1998.

MARCUS, George. Ethnography in/ofthe world system: the emergente of the multi-sited ethnography. Annual Review of Anthropology, v.24, p. 95-117.1995

MÁRMORA, Lelio. Las políticas de migraciones internacionales. Buenos Aires: Paidos, 2002.

MARTES, Ana Cristina Braga. Brasileiros nos Estados Unidos. Um estudo sobre imigrantes em Massachussets. São Paulo: Paz e Terra,2000.

MENDES, M. Manuela. Um olhar sobre a identidade e a alteridade: Nós, os Ciganos e os Outros, os NãoCiganos. Presentado en el IV Congreso Portugués de Sociología, Coimbra, 2000. http://www.aps.pt/ivcong-actas/Acta058.PDF

MORALES, Eduardo; FIGUEROA, Rodrigo. Impactos socio culturales de las migraciones. IN: CONFERENCIA INTERNACIONAL LA MIGRACIÓN: Un Derecho Humano: Experiencias En América Del Sur, Santiago de Chile, 2004. Annais, Santiago de Chile: Editor, 2004.

PADILLA, Beatriz. Integration of Brazilian immigrants in Portuguese society: Problems and possibilities, apresentado na $9^{\text {a }}$ Metropolis Conference "Co-operative Migration Management: International, National and Local Answers, Geneva, Setembro, 2004a.

PADILLA, Beatriz. Imigrantes brasileiras: género, etnicidade e mercado de trabalho. IN: WORKSHOP MULHERES IMIGRANTES, Lisboa, nov. 2004. Comunicación presentada Lisboa: SOCIOUS-ISEG, Lisboa: Novembro, $2004 \mathrm{~b}$.

PADILLA, Beatriz. Redes sociales de los brasileros recién llegados a Portugal: ¿solidaridad étnica o empatía étnica?.Alternativas: Cuadernos de Trabajo Social, n. 14 (Alicante), p. 4961, 2006a.

PADILLA, Beatriz. Brazilian migration to Portugal: social Networks and ethnic solidarity. CIES-ISCTE Working Paper, n. 12, 2006b. Disponível em <http://cies.iscte.pt/documents/CIES-WP12.pdf>. Acesso em 2/10/2013.

PADILLA, Beatriz. A imigrante brasileira em Portugal: considerando o gênero na análise. In: MALHEIROS, Jorge Macaísta (Org.), Imigração Brasileira em Portugal. Lisboa: Alto Comissariado para a Imigração e Diálogo Intercultural, 2007, p.113-135.

PADILLA, Beatriz.. Novas configurações das migrações brasileiras na Europa: uma reflexão e proposta de agenda. In PADILLA, Beatriz et al. Novas e velhas configurações da imigração brasileira na Europa. Atas do $2^{\circ}$ Seminário de Estudos sobre a Imigração Brasileira na Europa. Lisboa: ISCTE - Instituto Universitário de Lisboa, 2012, p.1-5.

PADILLA, Beatriz; GOMES, Mariana y FERNANDES, Gleiciani. Ser brasileira em Portugal: 
imigração, género e colonialidade. Atas do $1^{\circ}$ Seminário de Estudos sobre Imigração Brasileira na Europa, Barcelona, 2010.

PADILLA, Beatriz y GOMES, Mariana Selister. Racismo contra Mulheres Brasileiras em Portugal? Algumas Reflexões. Atas do VII Congresso Português de Sociologia: Sociedade, Crise e Reconfigurações, APS, 2012.

PADILLA, Beatriz y ORTIZ, Alejandra. Fluxos migratórios em Portugal: do boom migratório à desaceleração no contexto de crise. Balanço e desafios. Revista REMHU, v.20, n.39, JulDec, 2012. Disponível em <http://www.csem.org.br/remhu>. Acesso em 2/10/2013.

PARELLA, Sonia. Los vínculos afectivos y de cuidado en las familias transnacionales. Migrantes ecuatorianos y peruanos en España. Migraciones Internacionales, v. 4, n. 2, p.151- 188, 2007.

PEIXOTO, João y FIGUEIREDO, Alexandra. Imigrantes brasileiros e mercado de trabalho em Portugal. In: MALHEIROS, Jorge (Ed.). Imigração brasileira em Portugal. Lisboa: ACIDI, 2007, p. 87-111.

PONTES, Luciana. Mulheres brasileiras na mídia portuguesa. Cadernos Pagu, n. 23, p. 229256, 2004.

VERTOVEC, Steven. Transnationalism and Identity. Journal of Ethnic and Migration Studies, v. 27, n.4, p. 573-582, 2001.

WARD, Carolina; STYLES, Irene. Lost and Found: Reinvention of the self following migration. Journal of Applied Psychoanalytic Studies, v 5, n. 3, p. 51-57, 2003. YING, Yu-Wen. Migration and cultural orientation: an empirical test of the psychoanalytic theory in Chinese-Americans. Journal of Applied Psychoanalytic Studies, v. 3, n.4, p.409430, 2001. 
Recebido em: 26/03/2014 Aprovado em: 26/05/2014

Universidade do Estado de Santa Catarina - UDESC

Centro de Ciências Humanas e da Educação - FAED

Revista PerCursos

Volume 15 - Número 28 - Ano 2014 revistapercursos@gmail.com 